\title{
A 56-Day Oral Toxicity Study of the Aqueous Extract of Rapanea melanophloeos (L.) Mez in Rats
}

\author{
Hesbon Z. Amenya, ${ }^{1}$ James M. Mbaria, ${ }^{1}$ Andrew G. Thaiyah, ${ }^{2}$ \\ Grace N. Thoithi, ${ }^{3}$ and Peter K. Gathumbi ${ }^{4}$ \\ ${ }^{1}$ Department of Public Health, Pharmacology and Toxicology, University of Nairobi, P.O. Box 29053-00625, Nairobi, Kenya \\ ${ }^{2}$ Department of Clinical Studies, University of Nairobi, P.O. Box 29053-00625, Nairobi, Kenya \\ ${ }^{3}$ School of Pharmacy, University of Nairobi, P.O. Box 19676-00202, Nairobi, Kenya \\ ${ }^{4}$ Department of Veterinary Pathology, Microbiology and Parasitology, University of Nairobi, P.O. Box 29053-00625, Nairobi, Kenya
}

Correspondence should be addressed to Hesbon Z. Amenya; bonny@students.uonbi.ac.ke

Received 4 August 2016; Revised 7 November 2016; Accepted 1 December 2016

Academic Editor: Victor Kuete

Copyright ( 2016 Hesbon Z. Amenya et al. This is an open access article distributed under the Creative Commons Attribution License, which permits unrestricted use, distribution, and reproduction in any medium, provided the original work is properly cited.

Rapanea melanophloeos is a tropical tree that is extensively utilized in African traditional medicine to treat helminthiases, tuberculosis, and heart-water. As with many other medicinal plants, there is insufficient information regarding the safety of therapeutic $R$. melanophloeos extracts. An aqueous extract of $R$. melanophloeos stem bark was administered to Sprague Dawley rats at doses of $100 \mathrm{mg} / \mathrm{kg}, 300 \mathrm{mg} / \mathrm{kg}$, and $1000 \mathrm{mg} / \mathrm{kg}$ for 56 days to characterize its potential toxicity after prolonged dosing. Blood samples were obtained fortnightly for serum chemistry and hematology, while organs were collected at the end of the study. The extract caused an increase in organ weight indices of the kidneys and testis at $300 \mathrm{mg} / \mathrm{kg}$ and $1000 \mathrm{mg} / \mathrm{kg}$. Hematological and biochemical examination revealed a drop in leukocyte counts and the hematocrit at $1000 \mathrm{mg} / \mathrm{kg}$ dose level, while there was a general but nondose-related elevation in alkaline phosphatase activity. There were time-associated variations in the hematological and clinical chemistry parameters at days 28,42 , and 56 in all dose levels, but most values remained within physiological limits. No pathological lesions were evident at histopathology after treatment with the extract. Our data shows that the aqueous extract of $R$. melanophloeos is not likely to be toxic at the doses tested and provides support to its medicinal use.

\section{Introduction}

Medicinal plants continue to play a crucial role in the provision of healthcare in ethnomedicine and ethnoveterinary medicine [1]. They have been utilized this way since the history of mankind [2,3]. Given the high cost of mainstream medicine on one hand and easy accessibility of herbal remedies on the other hand, medicinal plants become an attractive healthcare option for less economically endowed populations. Up to 50,000-70,000 plant species, from trees to lichens, have been utilized as medicinal plants [4]. On the contrary, only a small number of these medicinal plant species have been scientifically investigated for safety and efficacy [5]. This fact calls for urgent toxicological examination of widely used medicinal plants and extracts.
Rapanea melanophloeos (Myrsinaceae) is extensively utilized as a herbal remedy in traditional medicine in most of southern and eastern Africa. In South Africa, the stem bark is particularly widely used, especially when prepared as a decoction [6]. Among its many therapeutic applications, $R$. melanophloeos is commonly utilized in the treatment of helminthiasis $[7,8]$, tuberculosis $[9,10]$, and heart-water [6]. It is also used as an expectorant, emetic, and astringent [10], as an anti-inflammatory and analgesic [11]. R. melanophloeos contains the benzoquinones embelin and rapanone [12], tannins $[10,13]$, and saponins [14] as the main biologically active components. Pharmacologically, R. melanophloeos possesses anthelmintic activity [15], molluscicidal activity [14, 16], anticoagulation properties [10], and fungicidal activity [14]. 
Also, anticancer activity has been reported by Fouche et al., the antimalarial activity of the leaf extracts by Clarkson et al., and the antimycobacterial activity by Lall and Meyer, 1999 [17].

Previously, in an acute toxicity study, we found that the aqueous extract of $R$. melanophloeos practically nontoxic even at very high doses [18] and that its chloroformic extract does not induce toxicity related changes in organ structure and hematological and biochemical parameters after subacute oral administration for 28 days [19]. However, there is no toxicological evidence on effects of prolonged administration of the more widely utilized aqueous extract in ethnomedicine and ethnoveterinary medicine. In the current study we sought to analyze the 56 day oral toxicity of $R$. melanophloeos stem bark aqueous extract in laboratory rats. During this period, we monitored the clinical signs and hematological, clinical chemistry parameters of the animals. Our data show that the extract is nontoxic, since no organ pathology resulted from its administration despite the alterations in hematological and biochemical parameters. This study supports the prudent use of $R$. melanophloeos in ethnomedicine and ethnoveterinary medicine at the dose levels tested.

\section{Methods}

2.1. Plant Material. The bark of $R$. melanophloeos was harvested in June 2009 from a natural forest in Narok, Kajiado County, Kenya, with the help of an experienced local herbalist at GPS coordinates S 0 55.237, E 35 54.432. Botanical authentication was carried out at the Department of Land Resources Management and Agricultural Technology, University of Nairobi, by the department's taxonomists, and a voucher specimen was preserved (number 27/2009) at the departmental herbarium. The plant name was verified at http://www.theplantlist.org (Accessed April 17, 2016).

The bark was air-dried and ground into a fine powder, which was then extracted using distilled water by boiling $10 \mathrm{~g}$ batches in $100 \mathrm{~mL}$ water for $5 \mathrm{~min}$. The extract was filtered through cotton gauze and a double layer of Whatman's filter paper number 4 and then centrifuged at $5000 \mathrm{rpm}$ for $5 \mathrm{~min}$. It was then freeze-dried in a Heto Drywinner 3 freeze drier (HetoHolten, Germany) and stored at $-20^{\circ} \mathrm{C}$. The percentage yield was $12.2 \%(\mathrm{w} / \mathrm{w})$.

2.2. Experimental Animals. Sprague Dawley rats aged 6-8 weeks were obtained from the Central Veterinary Investigation Laboratories (Kabete, Kenya). They were randomly allocated and housed in cages, each containing 5 rats, male and females separately. The animals had free access to commercial rat chow and drinking water and were allowed 7 days for acclimatization prior to commencement of the experiments. While conducting this study, we adhered to the internationally accepted principles for laboratory animal use and care as outlined in the European Community guidelines (EEC Directive of 1986; 86/609/EEC). The animal experiments were reviewed and approved by the University of Nairobi's Board of Postgraduate Studies (Nairobi, Kenya).
2.3. Toxicity Study. This toxicological study was carried out following the Organization for Economic Cooperation and Development (OECD) repeated dose 28-day oral toxicity study guideline [20]. To test the time-linked effect of the extract on the test parameters, we prolonged the toxicity testing period to 56 days, within which we obtained blood samples at fortnight intervals. Forty animals were randomly allocated to three treatment groups of 5 animals per sex and to a control group. The plant extract was administered daily to the treatment groups at doses of $100 \mathrm{mg} / \mathrm{kg}, 300 \mathrm{mg} / \mathrm{kg}$, and $1000 \mathrm{mg} / \mathrm{kg}$ body weight based on individual bodyweights at day 0 and adjusted according to weekly weight changes. Controls were administered with the vehicle (physiological saline) daily for 56 days until the day prior to necropsy. The animals were carefully observed for clinical signs of toxicity.

2.3.1. Blood Sampling and Hematological Parameters. Blood was collected from the retro-orbital venous plexus of anaesthetized animals into Greiner ${ }^{\circledR}$ tubes containing heparin, as described by Moore, 2006 [21]. Blood samples were obtained from treatment and control groups before commencement of treatment and then fortnightly till the end of the study. Bleeding did not exceed recommended volumes [22]. Hematological parameters were analyzed using the MS4 Vet ${ }^{\circledR}$ hematology blood counter (Melet Schloesing Laboratories, Cergy-Pontoise Cedex, France). The parameters included total erythrocyte count (RBC), total leukocyte count (WBC), hemoglobin concentration, the hematocrit, mean corpuscular hemoglobin $(\mathrm{MCH})$, mean corpuscular hemoglobin concentration (MCHC), mean corpuscular volume (MCV), and thrombocyte count.

2.3.2. Biochemical Parameters. Heparinized plasma was obtained by centrifuging blood in heparin at $12,000 \mathrm{rpm}$ for $5 \mathrm{~min}$. Parameters analyzed were total protein, albumin, alkaline phosphatase (ALP), alanine aminotransferase (ALT), aspartate aminotransferase (AST), creatine kinase (CPK), creatinine, and blood urea nitrogen (BUN). These were evaluated using kits from DiaSys (Diagnostic Systems International, Germany) and Thermo Scientific (Thermo Electron, Australia and Fisher Diagnostics, USA).

2.4. Pathology. At the end of the study, all the experimental animals were euthanized and their carcasses subjected to general examination and necropsy. Pertinent gross pathologic observations in organ systems were recorded. The liver, kidney, heart, spleen, adrenals, lungs, testicles, and ovaries were weighed before fixation in $10 \%$ neutral buffered formalin.

Standard histopathological procedures were applied [23]. Formalin fixed tissues were trimmed at 2-3 mm thickness, embedded in paraffin, sectioned at 4-5 um thickness, and stained with haematoxylin and eosin (H\&E). Microscopic examination was done on the major organs and any organs that showed gross pathology, in all animals at the highest dose group. The findings were compared to parallel sections at lower dosage levels and from control animals.

2.5. Statistical Analysis. Data is presented as means and standard deviations for each parameter. Organ weight indices 


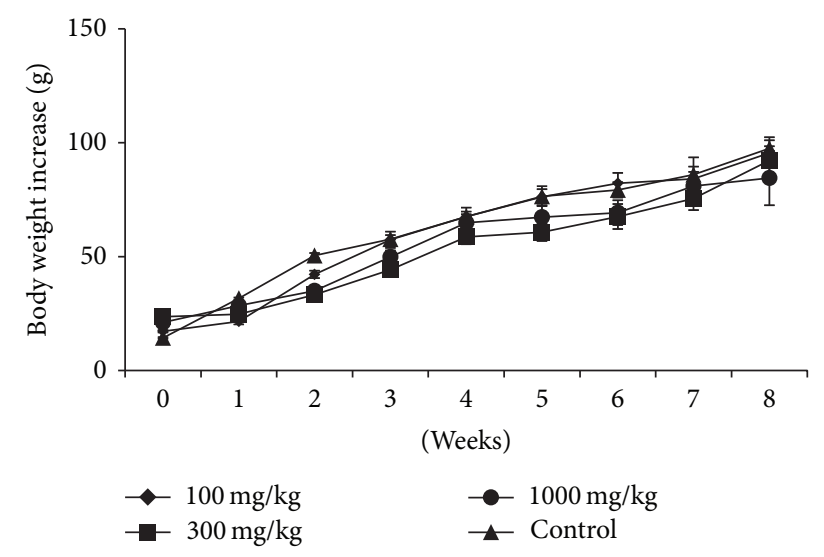

FIGURE 1: Body weight changes in rats dosed with the aqueous extract of Rapanea melanophloeos stem bark for 56 days. There was progressive weight gain in both control and treatment groups.

and weight changes were compared by one-way ANOVA, while biochemistry and hematology values were analyzed by two-way ANOVA using Stat View ${ }^{\circledR}$ (SAS Institute Inc., California, USA). The means contributing to variation were outlined using Fisher's least significant difference post hoc test. Differences were statistically significant if $p<0.05$.

\section{Results}

3.1. Clinical Observations. Dose levels of $100-1000 \mathrm{mg} / \mathrm{kg}$ body weight of the extract did not cause any signs of toxicity or deaths in the 8 weeks of treatment. The treatment groups gained weight progressively as in the controls (Figure 1).

3.2. Pathological Changes. Organ weight indices (OWI) were calculated as the ratio of the individual organ weight to the carcass weight at necropsy. The OWI of the kidneys at dosage level $1000 \mathrm{mg} / \mathrm{kg}(p=0.0080)$ and $300 \mathrm{mg} / \mathrm{kg}$ $(p=0.0327)$ were significantly increased compared to the control animals. The testes at dosage level $1000 \mathrm{mg} / \mathrm{kg}(p=$ $0.0150)$ and $300 \mathrm{mg} / \mathrm{kg}(p=0.0016)$ were also significantly heavier (Table 1). However, there were no significant gross or histopathological changes in any of the organs (Figure 2).

3.3. Hematology. There were a significant drop in $\mathrm{WBC}$ counts $(p=0.0246)$ and the hematocrit $(p=0.0348)$ at $1000 \mathrm{mg} / \mathrm{kg}$ dose level (Figures 3(a) and 3(c)) and MCV values at $300 \mathrm{mg} / \mathrm{kg}$ dose level $(p=0.0043)$ (Figure 4(a)) when compared to the controls, but the values were within the physiological limits for rats at all dosage levels. The $\mathrm{RBC}$, hemoglobin, $\mathrm{MCH}, \mathrm{MCHC}$, and thrombocytes were not significantly altered by any of the doses but timelinked variations occurred within the experimental period. In comparison to the controls, leukocyte counts of the $1000 \mathrm{mg} / \mathrm{kg}$ dose group had an overall decrease from day 14 to day 56, while values of the $100 \mathrm{mg} / \mathrm{kg}$ and $300 \mathrm{mg} / \mathrm{kg}$ group remained higher (Figure 3(a)). The RBC count increased significantly in all the groups from day 14 up to day 28 , notably at the $1000 \mathrm{mg} / \mathrm{kg}$ dose level. The most remarkable increase occurred at day 56 in the other dose groups
(Figure 3(b)). This trend in RBC count was replicated by that of the hematocrit (Figure 3(c)). Similarly, the hemoglobin concentration increased significantly $(p=0.0043)$, being higher than initial readings at days 14,28 , and 56 with variations between the dose groups (Figure 3(d)). On the other hand, the MCV took a steady decline towards day 56 , and values of the $300 \mathrm{mg} / \mathrm{kg}$ dose level remained lower than reference values [24] within the experimental period (Figure 4(a)). The $\mathrm{MCH}$ readings maintained a stable course up to day 42 after which they dropped sharply towards day 56 in all dose groups. Notably, the $1000 \mathrm{mg} / \mathrm{kg}$ dose group had a significant drop at day 28 , but values remained higher at day 56 (Figure 4(b)). The MCHC trend replicated that of the $\mathrm{MCH}$ (Figure 4(c)). Thrombocyte counts exhibited dose related increases at dosage levels $300 \mathrm{mg} / \mathrm{kg}$ and $1000 \mathrm{mg} / \mathrm{kg}$ from day 14 to day 28. This trend was lost on days 42 and 56. Overall, only the $100 \mathrm{mg} / \mathrm{kg}$ dose group showed a steady increase (Figure 4(d)). All thrombocyte counts remained lower than the physiological ranges [24]. This was also true for $\mathrm{RBC}$ and hematocrit and $\mathrm{MCH}$ and $\mathrm{MCHC}$ at day 56 that were higher and lower, respectively. It was observed that fluctuation in hematology parameters was not dose related over the entire experimental period, but considering the overall effect of both dose and time, the two parameters that showed a dose relationship were the WBC (Figure 3(a)) and the hematocrit (Figure 3(c)), being significantly lower at dose $1,000 \mathrm{mg} / \mathrm{kg}$ than those of control group and decreasing step wise with dose. However, the overall effect of dose and time for both values were well within the physiological limits for the laboratory rat.

3.4. Clinical Chemistry. Considering the cumulative overall effect of dose and time, there was a significant elevation in ALP ( $p=0.0034)$ activity at all the dose levels when compared to the controls, but this elevation did not show a dose related pattern since the overall effect at dose $300 \mathrm{mg} / \mathrm{kg}$ was slightly higher than at $1,000 \mathrm{mg} / \mathrm{kg}$. Levels of ALP were within the physiological limit, the overall effect of dose notwithstanding (Figure 5(c)). Also, there was a noticeable nondose-related fluctuation in CPK activity peaking at day 42 (as did other enzymatic parameters) and then declining to levels slightly above the pretreatment values but within the physiological limit (Figure 6(b)). The rest of the biochemical parameters remained unaltered but showed time-related variations within the experimental period.

In comparison with the pretreatment readings, total protein increased significantly $(p<0.0001)$ on day 14 , day 28 , day 42 , and day 56 . The trends showed a steady increase in total protein at all dose levels up to day 42, upon which they declined to day 56 (Figure 5(a)). Albumin levels fluctuated around $3 \mathrm{~g} / \mathrm{dL}$ at all dosage levels and controls. On day 56, however, they showed a slight but significant decline from the pretreatment values in all dose levels and the control group $(p=0.0148)$ (Figure 5(b)). The AST activity declined significantly $(p<0.0001)$ at day 14 , day 28 , and day 56 . There was a modest increment at day 42 in the controls, $100 \mathrm{mg} / \mathrm{kg}$ and $1000 \mathrm{mg} / \mathrm{kg}$ dose levels (Figure 5(d)). Values on day 0 and day 42 surpassed the physiological range [25]. 
TABLE 1: Effect of the aqueous extract of Rapanea melanophloeos on organ weight indices of rats dosed for 56 days.

\begin{tabular}{lcccc}
\hline Organ & Control & $100 \mathrm{mg} / \mathrm{kg}$ & $300 \mathrm{mg} / \mathrm{kg}$ & $1000 \mathrm{mg} / \mathrm{kg}$ \\
\hline Liver & $4.32 \pm 0.54$ & $4.78 \pm 0.38$ & $4.31 \pm 0.46$ & $0.63 \pm 0.34$ \\
Spleen & $0.46 \pm 0.10$ & $0.48 \pm 0.14$ & $0.42 \pm 0.12$ & $0.36 \pm 0.10$ \\
Kidney & $0.72 \pm 0.07$ & $0.85 \pm 0.13$ & $0.44 \pm 0.09$ & $0.92 \pm 0.13^{\mathrm{a}}$ \\
Heart & $0.37 \pm 0.03$ & $0.41 \pm 0.06$ & $0.14 \pm 0.04$ & $0.45 \pm 0.10$ \\
Thymus & $0.13 \pm 0.04$ & $0.14 \pm 0.06$ & $0.04 \pm 0.01$ & $0.09 \pm 0.03$ \\
Adrenals & $0.03 \pm 0.01$ & $0.04 \pm 0.01$ & $1.45 \pm 0.18^{\mathrm{a}}$ & $0.04 \pm 0.01$ \\
Testes & $0.93 \pm 0.16$ & $1.17 \pm 0.28$ & $0.03 \pm 0.02$ & $1.33 \pm 0.04^{\mathrm{a}}$ \\
Ovaries & $0.05 \pm 0.01$ & $0.07 \pm 0.02$ & $0.04 \pm 0.02$ \\
\hline
\end{tabular}

The values are expressed as mean \pm standard deviation $\left(n=5\right.$ animals/sex/dose). ${ }^{a}$ Significant difference from control group ( $p<0.05$, one-way ANOVA followed by Fisher's PLSD post hoc test); organ weight index = (actual organ weight/final body weight $) \times 100$.

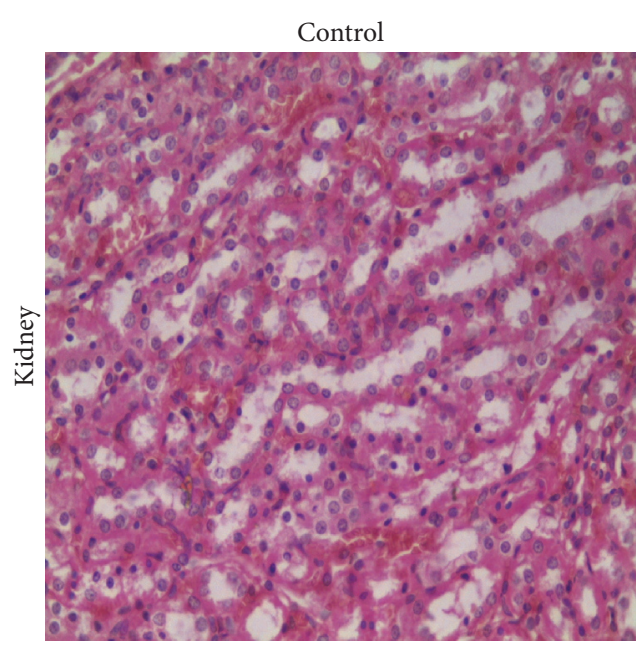

(a)

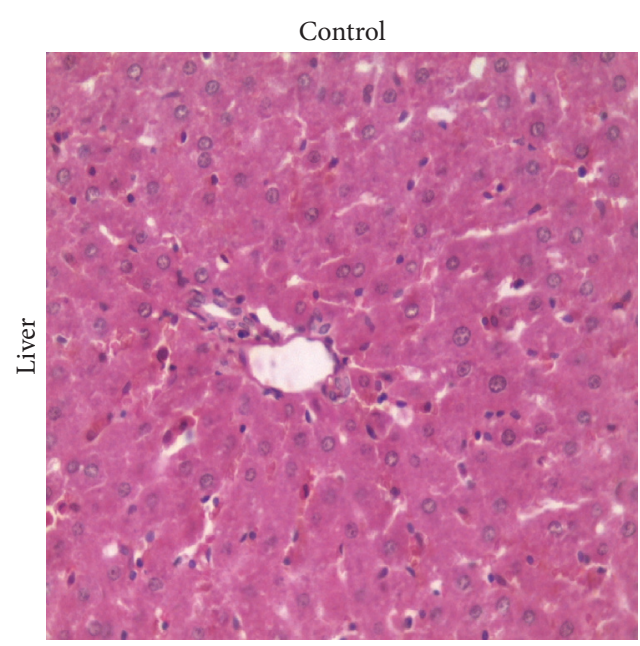

(c)

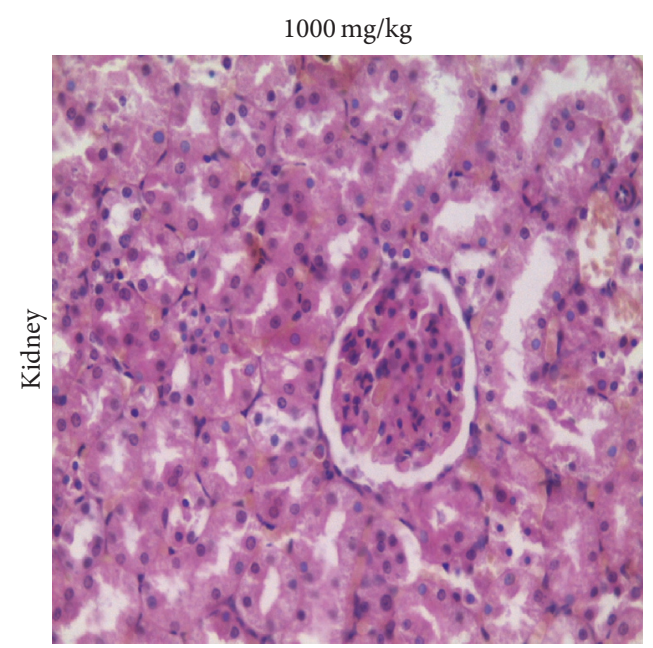

(b)

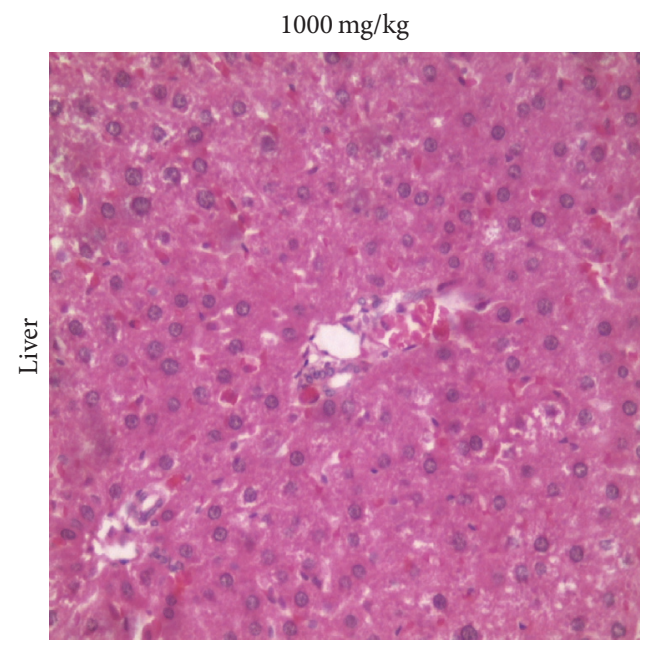

(d)

FIGURE 2: Representative photomicrographs of rats dosed with $1000 \mathrm{mg} / \mathrm{kg}$ R. melanophloeos aqueous extract for 56 days. (a) The kidney of a control rat showing normal histoarchitecture, (b) the kidney of a treated rat with preserved tubular and glomerular architecture, (c) the liver of a control rat displaying normal histoarchitecture, and (d) the liver of a treated rat showing normal microscopic appearance. $\mathrm{H} \& \mathrm{E} \times 400$. 


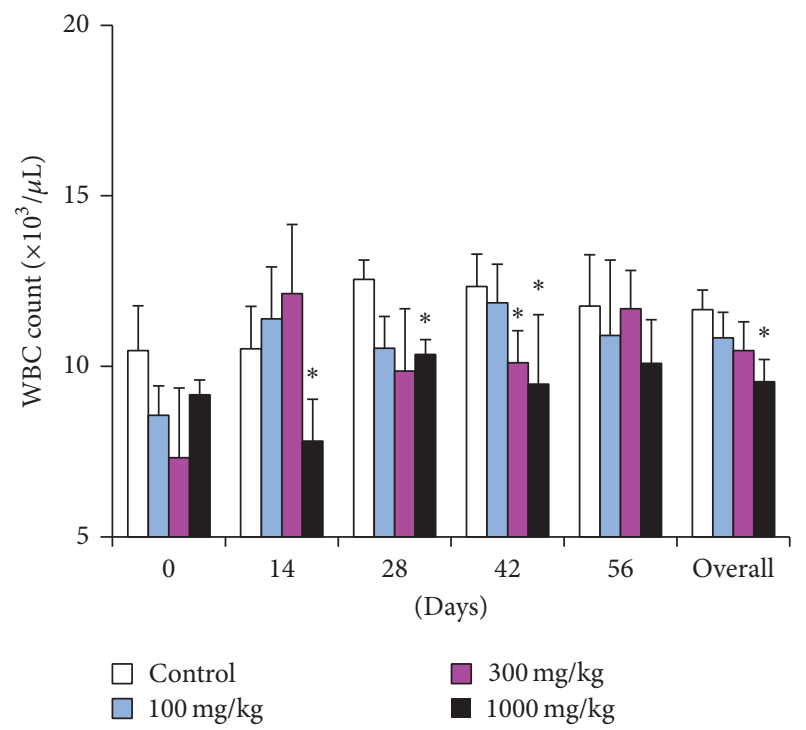

(a)

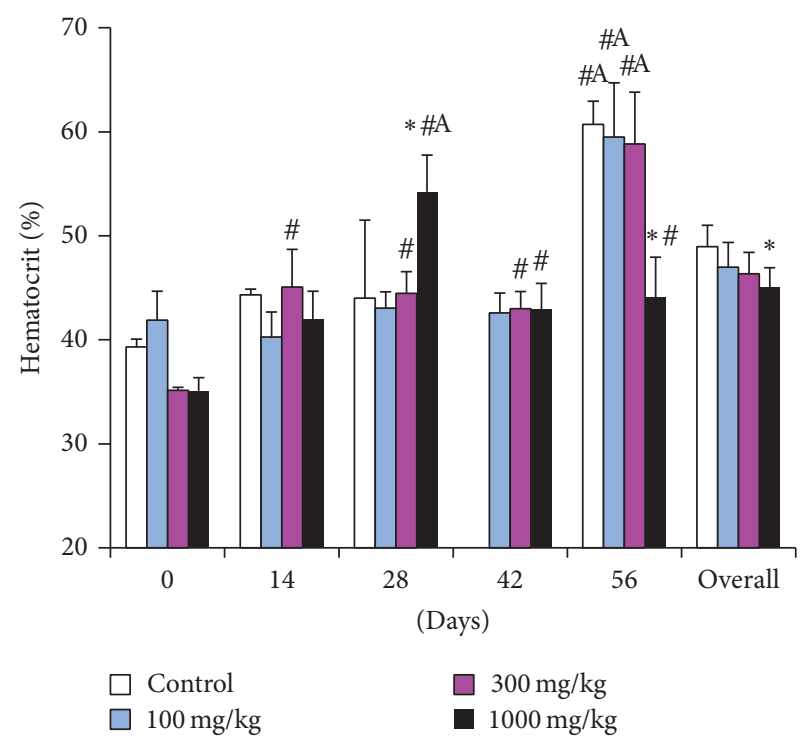

(c)

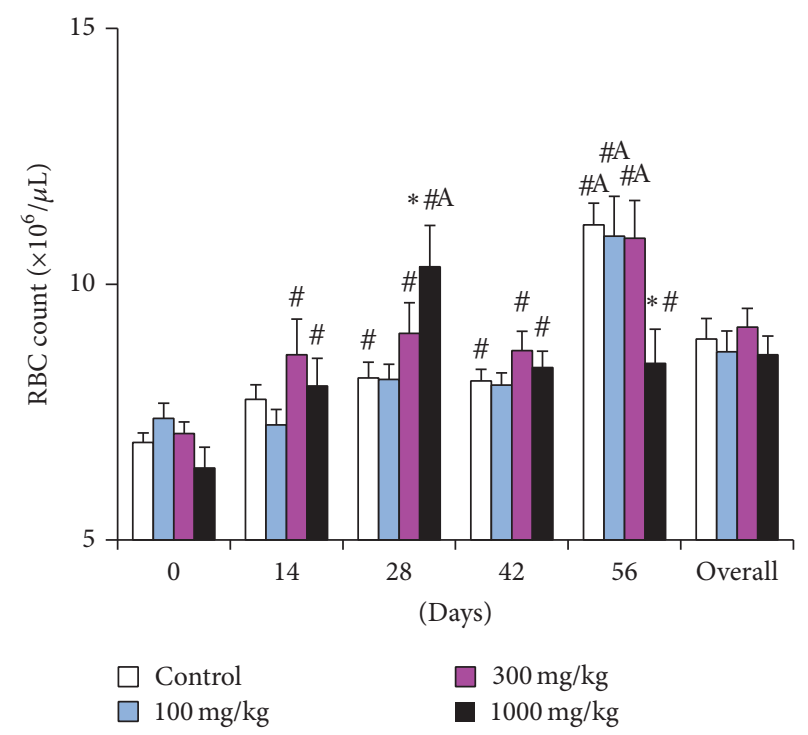

(b)

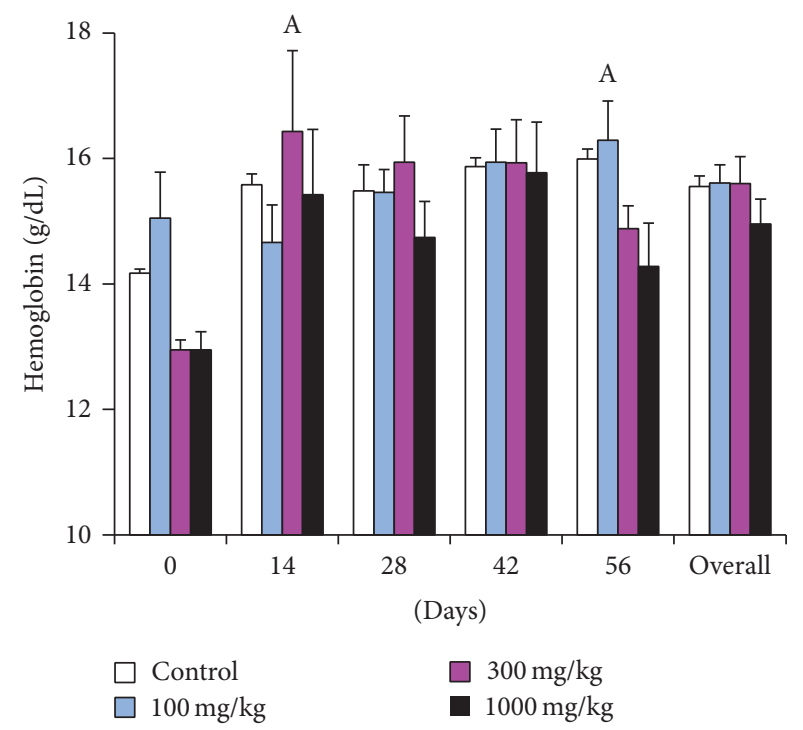

(d)

FiguRE 3: Hematological parameters of rats dosed with the aqueous extract of Rapanea melanophloeos stem bark for 56 days. Samples were obtained and analyzed fortnightly; (a) leukocyte count, (b) red blood cell count, (c) hematocrit, and (d) hemoglobin. Overall values are the summary of readings at all time points. * indicates significant difference from the control means $(p<0.05$, two-way ANOVA followed by Fisher's PLSD post hoc test); \# indicates significant difference from pretreatment readings $(p<0.05)^{\mathrm{A}}$ values are different from the reference ranges [24].

The ALT activity had nondose-dependent increases at day 42 in the controls and the highest dose level. At day 28, however, there were significant decreases in the $300 \mathrm{mg} / \mathrm{kg}$ and $1000 \mathrm{mg} / \mathrm{kg}$ dose groups (Figure 6(a)). The BUN levels fluctuated closely to the control values and maintained a steady trend across the experimental period but peaked ( $p=$ 0.0003 ) at day 42 , particularly in the highest dose group and then declined at day 56 (Figure 6(c)). Creatinine decreased steadily and significantly $(p<0.0001)$ from day 14 onwards to day 56 in all dose levels and the control group (Figure 6(d)). Taking the overall effect of dose in the entire experiment, the biochemical parameters fluctuated around the control, pretreatment values, or physiological limits [25].

\section{Discussion}

Safety evaluation and pharmacological information on medicinal plants is essential to validate their therapeutic application in traditional medicine and to enable informed bioprospecting. In a previous study, we investigated the acute toxic effects of high doses of $R$. melanophloeos aqueous extract in brine shrimps and rats [18]. This study was followed by a 


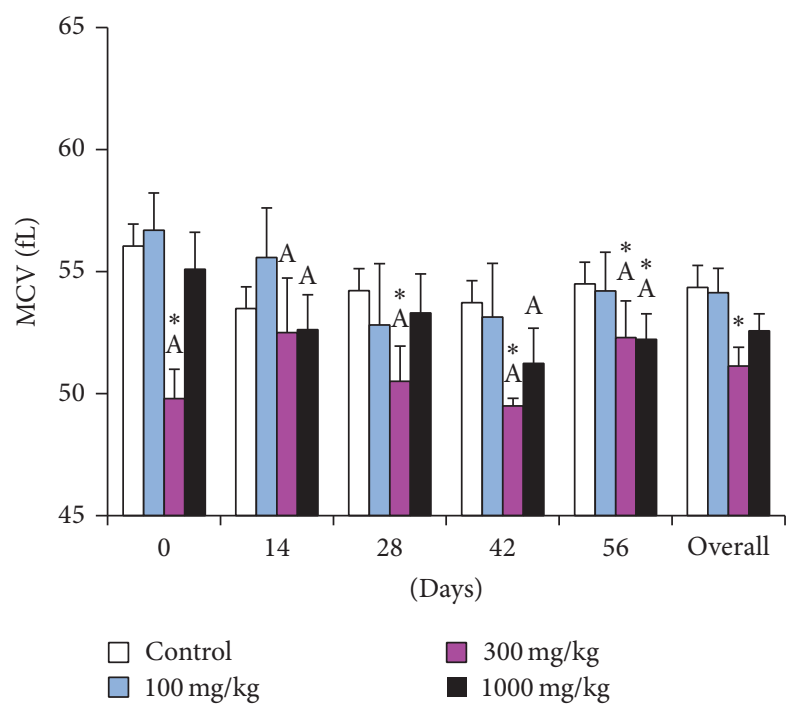

(a)

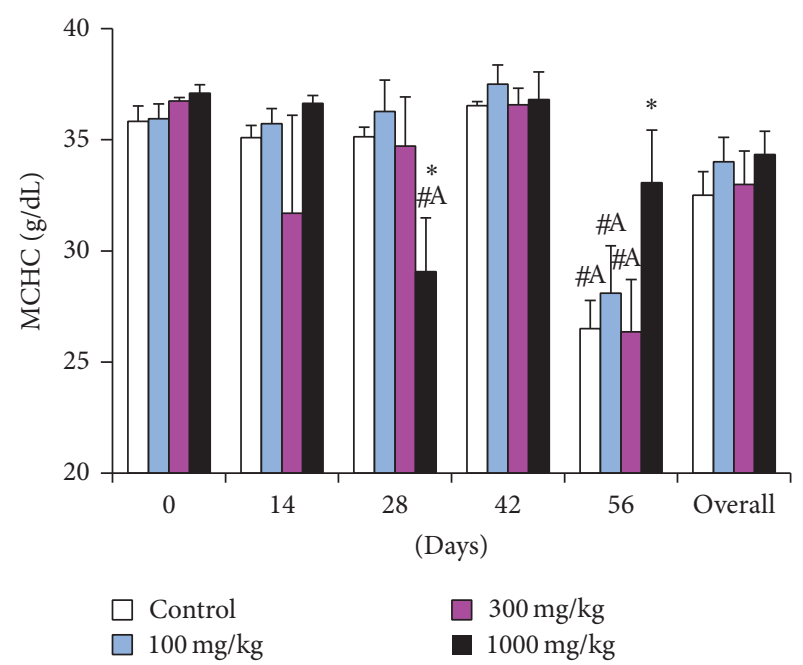

(c)

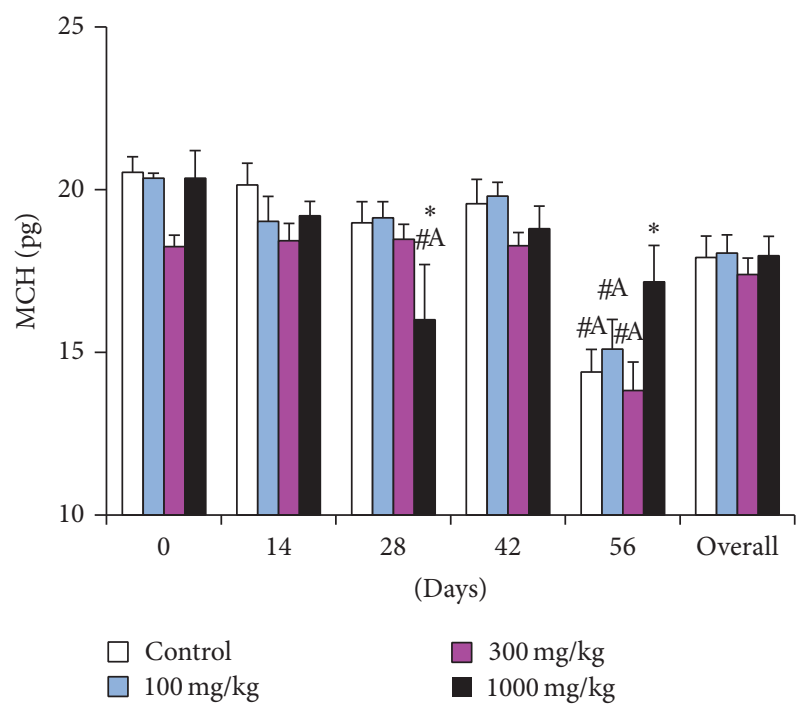

(b)

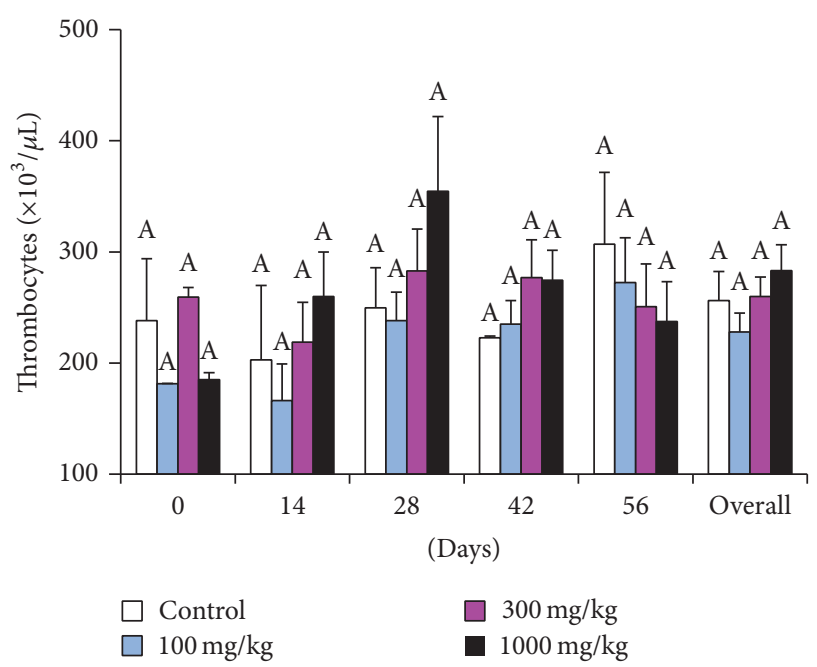

(d)

Figure 4: Hematological parameters of rats dosed with the aqueous extract of Rapanea melanophloeos stem bark for 56 days. Samples were obtained and analyzed fortnightly; (a) mean corpuscular volume, (b) mean corpuscular hemoglobin, (c) mean corpuscular hemoglobin concentration, and $(\mathrm{d})$ thrombocyte count. Overall values are the summary of readings at all time points. * indicates significant difference from the control means ( $p<0.05$, two-way ANOVA followed by Fisher's PLSD post hoc test); \# indicates significant difference from pretreatment readings $(p<0.05)^{A}$ values are different from the reference ranges [24].

subacute oral toxicity study of the chloroformic extract [19]. In both studies the extracts of $R$. melanophloeos were found to be nontoxic. Similarly, our current study provides additional evidence of the safety of $R$. melanophloeos stem bark aqueous extract after prolonged repeated dosing up to $1,000 \mathrm{mg} / \mathrm{kg}$ bodyweight for 8 weeks.

In the current study, the aqueous extract did not alter the weight gain or cause adverse clinical signs when compared to the controls. This signifies that the aqueous extract at these doses does not adversely affect the growth rate/body weight gain and corroborates several studies of other medicinal plants confirming their safety $[26,27]$. We observed that the relative organ weights of the kidneys and testis were significantly increased at 300 and $1000 \mathrm{mg} / \mathrm{kg}$ dosage levels.
However, hypertrophy was not evident at histopathology. Further, an analysis of biochemical parameters did not reveal renal insufficiency or soft tissue injury. We therefore concluded that this increase may be of no toxicological significance.

One strength of our study was the fortnight evaluation of hematological and clinical chemistry parameters, to generate a time-course profile of the effect of the extract on these parameters. On hematological examination we observed a decrease in leukocyte counts of the highest dosage level $(1,000 \mathrm{mg} / \mathrm{kg})$. On the other hand, since the counts remained within normal ranges [24] and above the pretreatment levels, this extract may have had a mild effect on lymphopoiesis and granulopoiesis. Fluctuation of leukocytes is also associated 


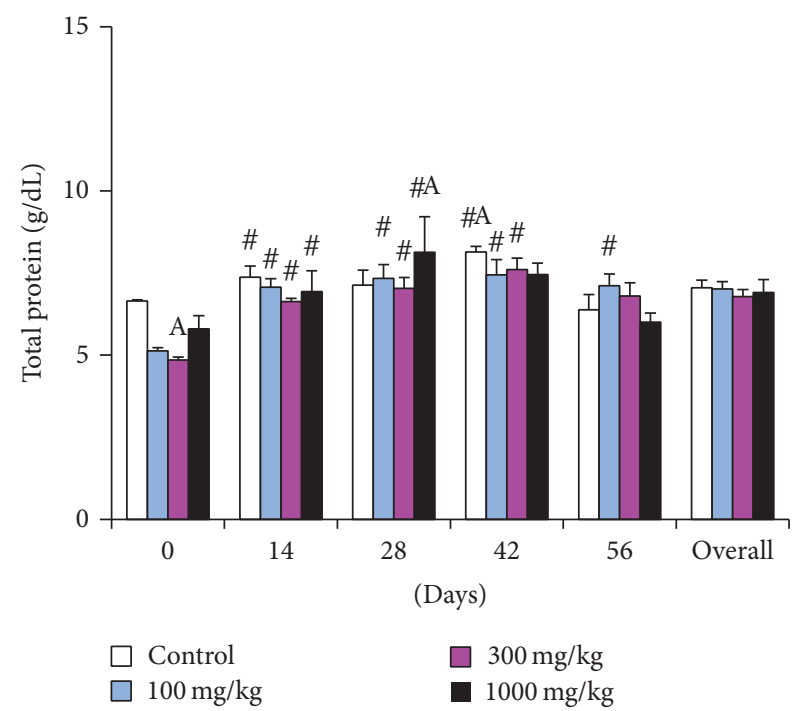

(a)

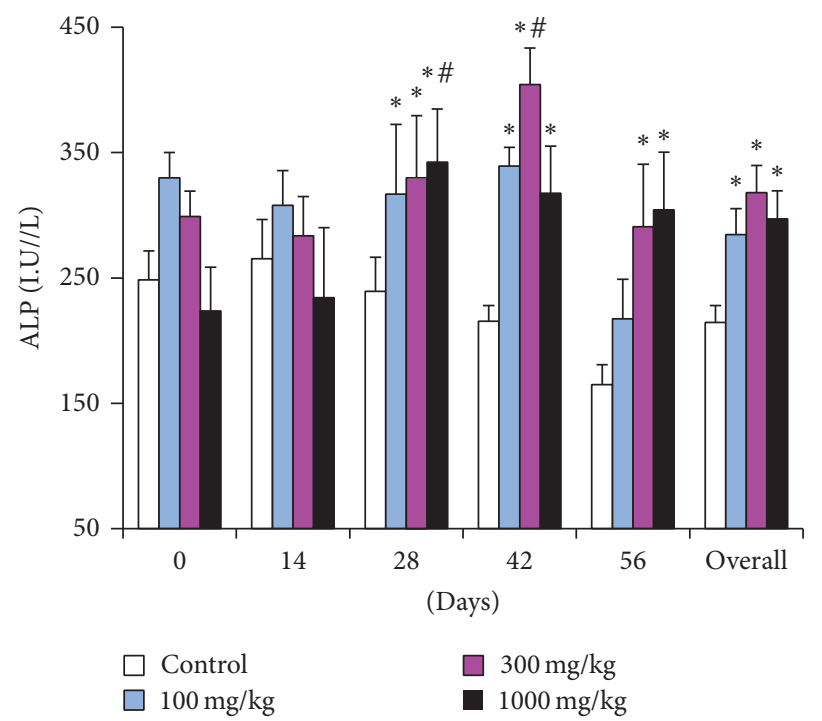

(c)

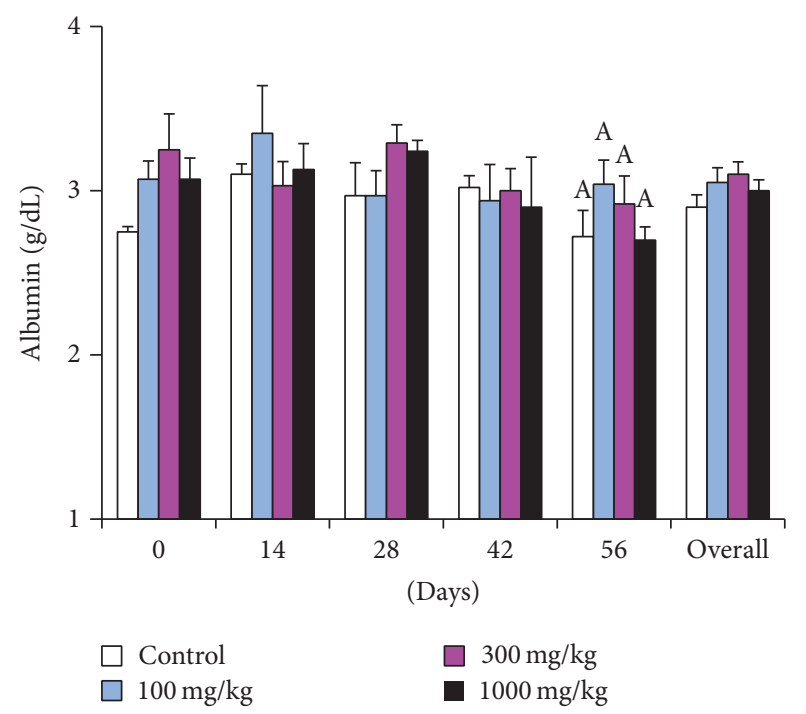

(b)

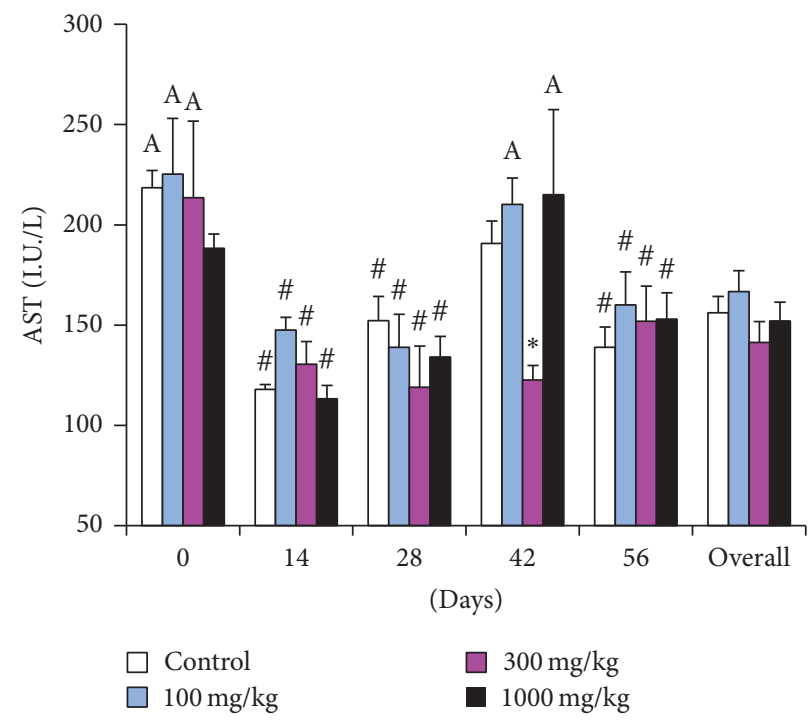

(d)

Figure 5: Clinical chemistry parameters of rats dosed with the aqueous extract of Rapanea melanophloeos stem bark for 56 days. Samples were obtained and analyzed fortnightly; (a) total protein, (b) albumin, (c) alkaline phosphatase activity, and (d) aspartate aminotransferase activity. Overall values are the summary of readings at all time points. $*$ indicates significant difference from the control means $(p<0.05$, two-way ANOVA followed by Fisher's PLSD post hoc test); \# indicates significant difference from pretreatment readings $(p<0.05) .{ }^{\mathrm{A}}$ Values are different from reference ranges [25].

with progression in age $[25,28]$. The $\mathrm{RBC}$ counts were not affected at any of the doses, except for a significant increase in the RBC count from day 14 to day 56 in all the dose levels. Consequently, the hematocrit and the hemoglobin also increased from day 14 onwards. We could only attribute this observation to relative polycythemia resulting from changes in body fluid dynamics during in vivo experimental toxicity evaluation [29]. Additionally, Petterino and ArgentinoStorino report that hematocrit generally increases in rats with progression of age. The observed increase in hematocrit and RBC values was corroborated by other erythrocytic indices, namely, $\mathrm{MCH}$ and $\mathrm{MCHC}$ which correspondingly decreased at similar time points alongside relatively stable hemoglobin values. The $\mathrm{MCH}$ and $\mathrm{MCHC}$ are calculated from hemoglobin, RBC counts, and the hematocrit, respectively. An increase in the RBC or hematocrit will directly reflect in a decrease of the $\mathrm{MCH}$ and $\mathrm{MCHC}$, respectively [30]. These trends were observed in our previous subacute toxicity study of the chloroformic extract [19] and are not likely to have arisen from the toxicity of the extract. The MCV is an index of the volume of RBCs which decreases in microcytic anemia or increases in macrocytic anemia [31]. The MCV decline in the $300 \mathrm{mg} / \mathrm{kg}$ group was not dose related since the effect was not compounded at the next higher dose 


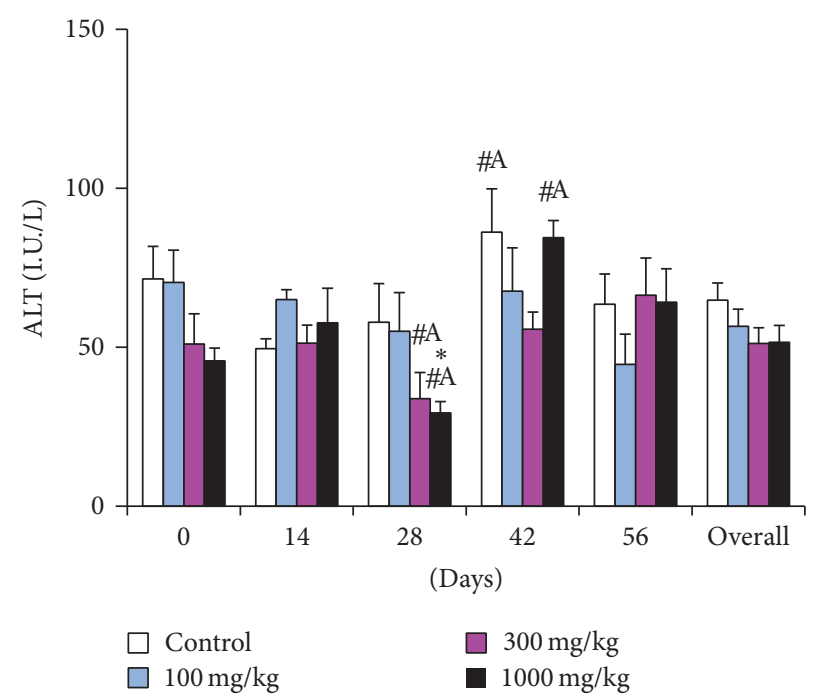

(a)

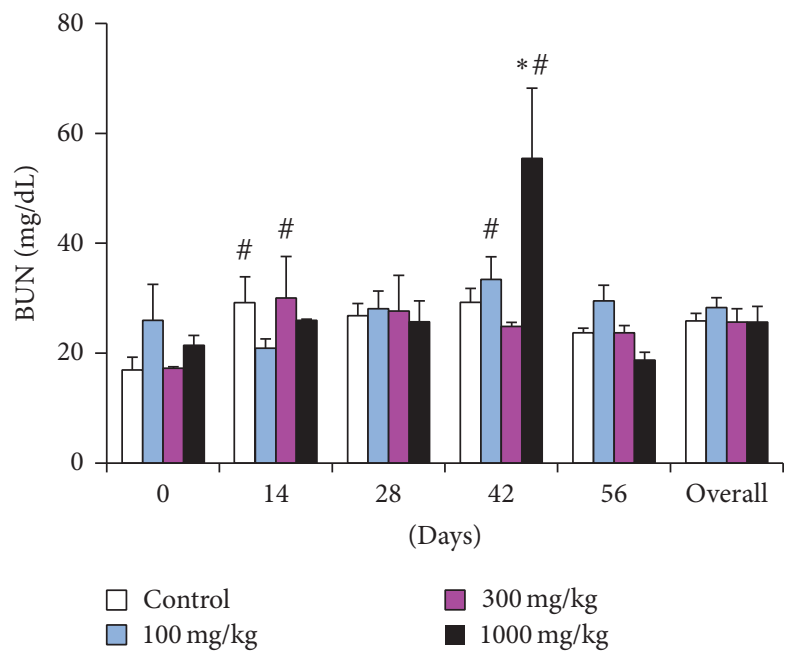

(c)

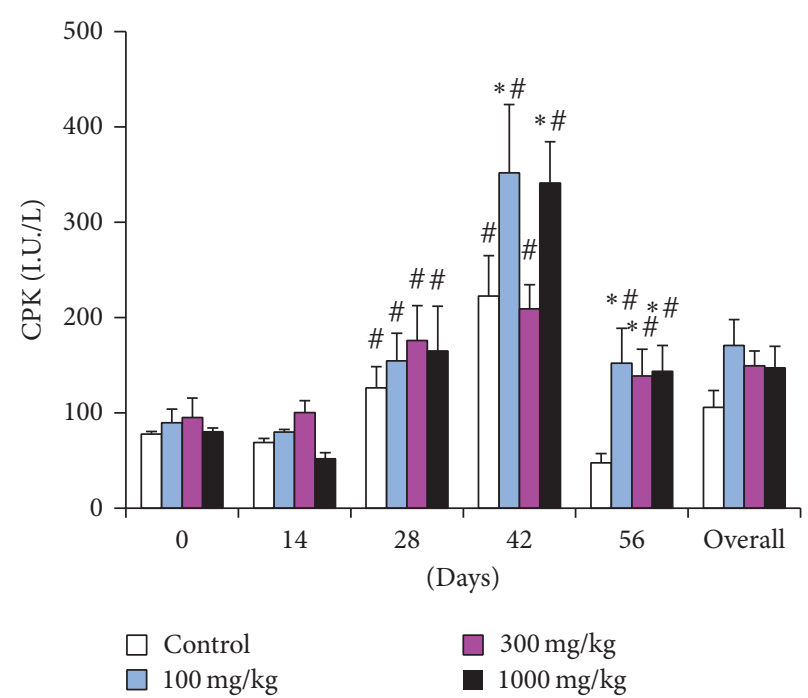

(b)

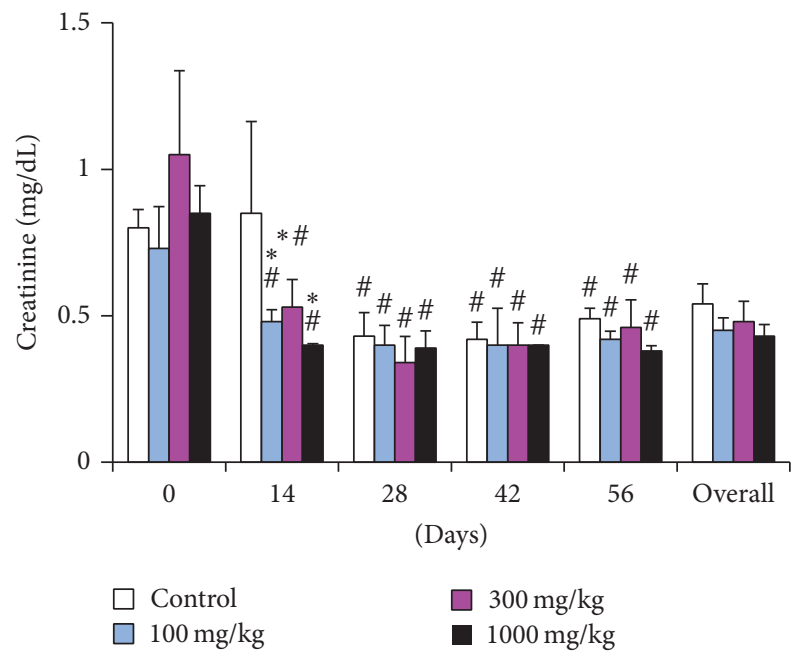

(d)

FIGURE 6: Clinical chemistry parameters of rats dosed with the aqueous extract of Rapanea melanophloeos stem bark for 56 days. Samples were obtained and analyzed fortnightly; (a) alanine aminotransferase activity, (b) creatine kinase activity, (c) blood urea nitrogen, and (d) creatinine. Overall values are the summary of readings at all time points. $*$ indicates significant difference from the control means $(p<0.05$, two-way ANOVA followed by Fisher's PLSD post hoc test); \# indicates significant difference from pretreatment readings $(p<0.05) .{ }^{\mathrm{A}}$ Values are different from reference ranges [25].

group. It may have resulted from interanimal variations and individual animal idiosyncrasies. Thrombocyte counts in the entire study fell below the reference ranges. There is evidence that heparin can cause platelet aggregation [32]. This could explain the low thrombocyte counts. On the other hand, Long Evans rats have been reported to have thrombocyte counts of up to $121-460 \times 10^{3} / \mu \mathrm{L}$ [24]. We therefore propose that the extract did not alter thrombopoiesis or platelet function.

An analysis of changes in clinical chemistry parameters within prolonged toxicity studies gives an insight into the mechanism of toxicity of a chemical and the target organ of toxicity [33]. In this study, ALP activity showed a nondoserelated increase. The significant elevation of ALP plasma activity in the treatment groups may have been caused by embelin, the main bioactive principle in $R$. melanophloeos. In an earlier study, embelin caused a significant elevation in liver ALP after 6 weeks of administration [34]. We also observed a slight increase in ALP after dosing rats with the chloroformic extract [19], but in both studies, the values did not exceed the physiological limits and they were not dose related.

Overall, in comparison with pretreatment readings, we observed an increase in the total protein, ALP, AST, ALT, and CPK on day 42 . These increases occurred concurrently in all the dose levels and the controls and were concomitant with some hematological alterations. We could only attribute this phenomenon to extraneous factors and biological variations resulting from inter- and intraanimal components. Collectively, fluid balance alterations may account for the increase 
in protein concentration as well as the previous increases in $\mathrm{RBC}$ and hematocrit. The increase in liver enzymes may have been caused by a perturbation of liver function. However, this alteration was not severe since most of the values were within physiological limits. These findings, taken together with the absence of histopathological alterations in the liver, show that $R$. melanophloeos may not be hepatotoxic. Other physiological variables such as age, sex, diet, restraint, and circadian effects may have contributed to the overall variation. Creatinine and BUN levels remained unchanged and together with the significant progressive decrease in creatinine from day 0 to day 56 indicate that the extract is nontoxic to the kidney. A significant elevation in the BUN occurred at day 42 , probably due to the prevailing alterations in liver function during this period, since BUN concentration is dependent on protein intake and turnover that relies on liver function.

In our earlier acute toxicity study we found the aqueous extract to be practically nontoxic [19]. Furthermore, data obtained from a subacute toxicity study of the chloroformic extract of R. melanophloeos has shown that it is not toxic [19]. Also, short-term toxicity evaluation of plants in the Myrsinaceae family showed that they were practically nontoxic to rats [35]. We attribute the low toxicity of $R$. melanophloeos to the innocuous nature of its main bioactive phytocomponents, embelin, and rapanone [36]. The results of this study confirm the fact that there are no reports of any adverse effects due to administration of $R$. melanophloeos water extracts in traditional medicine.

\section{Conclusions}

Overall, the hematology results indicate that the aqueous extract on prolonged administration may cause a slight decrease in leukocytes levels but could harbor no significant toxicological effect, because most of the hematologic parameters remained within the physiological ranges. The absence of histological alteration in organs affirms that prolonged administration of the water extract of $R$. melanophloeos at $100 \mathrm{mg} / \mathrm{kg}, 300 \mathrm{mg} / \mathrm{kg}$, and $1000 \mathrm{mg} / \mathrm{kg}$ will not adversely affect the function of body organs including the liver, kidney, and muscles. The aqueous extract of this plant can therefore be utilized in traditional medicine at oral dosages up to $1,000 \mathrm{mg} / \mathrm{kg}$ bodyweight, without posing a risk of prolonged toxicity to the patients.

\section{Competing Interests}

The authors declare that there is no conflict of interests regarding the publication of this paper.

\section{Acknowledgments}

The authors acknowledge the Director of Veterinary Services, Kenya, for providing animal facilities at the Central Veterinary Laboratories, Kabete, Kenya, and the support of Kenya Agricultural Productivity (KAPP Project Grant no. 2006036) for the supply of laboratory consumables for biochemistry, hematology, and histopathology. Special thanks are due to the technical staff Mr. John Mwongi, Ms. Jane Kamau, and Mrs. Jane Onsongo for technical assistance in tissue sectioning, hematological, and biochemical analysis.

\section{References}

[1] WHO, “Traditional medicine," 2004, http://www.who.int/mediacentre/factsheets/2003/fs134/en/.

[2] A. Gurib-Fakim, "Medicinal plants: traditions of yesterday and drugs of tomorrow," Molecular Aspects of Medicine, vol. 27, no. 1, pp. 1-93, 2006.

[3] R. A. Halberstein, "Medicinal plants: historical and crosscultural usage patterns," Annals of Epidemiology, vol. 15, no. 9, pp. 686-699, 2005.

[4] R. Verpoorte, H. K. Kim, and Y. H. Choi, "Plants as source of medicines. New perspectives," in Medicinal and Aromatic Plants. Agricultural, Commercial, Ecological, Legal, Pharmacological and Social Aspects, R. J. Bogers, L. E. Craker, and D. Lange, Eds., p. 75, Springer, 2006.

[5] C. W. Fennell, K. L. Lindsey, L. J. McGaw et al., "Assessing African medicinal plants for efficacy and safety: pharmacological screening and toxicology," Journal of Ethnopharmacology, vol. 94, no. 2-3, pp. 205-217, 2004.

[6] A. P. Dold and M. L. Cocks, "Traditional veterinary medicine in the Alice district of the Eastern Cape Province, South Africa," South African Journal of Science, vol. 97, no. 9-10, pp. 375-379, 2001.

[7] J. K. Muthee, D. W. Gakuya, J. M. Mbaria, P. G. Kareru, C. M. Mulei, and F. K. Njonge, "Ethnobotanical study of anthelmintic and other medicinal plants traditionally used in Loitoktok district of Kenya," Journal of Ethnopharmacology, vol. 135, no. 1, pp. 15-21, 2011.

[8] M. O. Nanyingi, J. M. Mbaria, A. L. Lanyasunya et al., "Ethnopharmacological survey of Samburu district, Kenya," Journal of Ethnobiology and Ethnomedicine, vol. 4, article no. 14, 2008.

[9] L. J. McGaw, N. Lall, J. J. M. Meyer, and J. N. Eloff, “The potential of South African plants against Mycobacterium infections," Journal of Ethnopharmacology, vol. 119, no. 3, pp. 482-500, 2008.

[10] J. M. Watt and M. G. Breyer-Brandwijk, The Medicinal and Poisonous Plants of Southern and Eastern Africa: Being an Account of Their Medicinal and Other Uses, Chemical Composition, Pharmacological Effects and Toxicology in Man and Animal, E. \& S. Livingstone, Edinburgh, UK, 1962.

[11] F. Chinemana, R. B. Drummond, S. Mavi, and I. De Zoysa, "Indigenous plant remedies in Zimbabwe," Journal of Ethnopharmacology, vol. 14, no. 2-3, pp. 159-172, 1985.

[12] J. O. Midiwo, A. Yenesew, B. F. Juma et al., "Bioactive compounds from some kenyan ethnomedicinal plants: myrsinaceae, polygonaceae and psiadia punctulata," Phytochemistry Reviews, vol. 1, no. 3, pp. 311-323, 2002.

[13] R. Mosa and G. Lazarus, "In vitro anti-platelet aggregation, antioxidant and cytotoxic activity of extracts of some Zulu medicinal plants," Journal of Natural Products, vol. 4, pp. 136146, 2011.

[14] K. Ohtani, S. Mavi, and K. Hostettmann, "Molluscicidal and antifungal triterpenoid saponins from Rapanea melanophloeos leaves," Phytochemistry, vol. 33, no. 1, pp. 83-86, 1993. 
[15] J. B. Githiori, J. Höglund, P. J. Waller, and R. L. Baker, "Anthelmintic activity of preparations derived from Myrsine africana and Rapanea melanophloeos against the nematode parasite, Haemonchus contortus, of sheep," Journal of Ethnopharmacology, vol. 80, no. 2-3, pp. 187-191, 2002.

[16] K. Hostettmann, A. Marston, K. Ndjoko, and J.-L. Wolfender, "The potential of African plants as a source of drugs," Current Organic Chemistry, vol. 4, no. 10, pp. 973-1010, 2000.

[17] N. Lall and J. J. M. Meyer, "In vitro inhibition of drug-resistant and drug-sensitive strains of Mycobacterium tuberculosis by ethnobotanically selected South African plants," Journal of Ethnopharmacology, vol. 66, no. 3, pp. 347-354, 1999.

[18] H. Amenya, G. N. Thoithi, A. G. Thaiyah, J. M. Mbaria, and P. K. Gathumbi, "In vitro and acute in vivo toxicity of the aqueous and chloroformic extracts of Rapanea melanophloeos (L) Mez," Kenya Veterinary, vol. 35, no. 2, pp. 77-85, 2013.

[19] H. Z. Amenya, P. K. Gathumbi, J. M. Mbaria, A. G. Thaiyah, and G. N. Thoithi, "Sub-acute toxicity of the chloroformic extract of Rapanea melanophloeos (L.) Mez in rats," Journal of Ethnopharmacology, vol. 154, no. 3, pp. 593-599, 2014.

[20] OECD, Test No. 407: Repeated Dose 28-Day Oral Toxicity Study in Rodents, Organisation for Economic Co-Operation and Development, Paris, France, 2008.

[21] D. M. Moore, "Hematology of the rat," in Schalm's Veterinary Hematology, D. J. Weiss and K. J. Wardrop, Eds., p. 1210, John Wiley \& Sons, 2006.

[22] K.-H. Diehl, R. Hull, D. Morton et al., "A good practice guide to the administration of substances and removal of blood, including routes and volumes," Journal of Applied Toxicology, vol. 21, no. 1, pp. 15-23, 2001.

[23] C. F. A. Culling, Handbook of Histopathological and Histochemical Techniques, Elsevier, 1974.

[24] A. P. Bolliger and N. E. Everds, "Hematology of laboratory rodents: mouse (Mus musculus) and rat (Rattus norvegicus)," in Schalm's Veterinary Hematology, D. J. Weiss and K. J. Wardrop, Eds., pp. 852-862, Blackwell, Hoboken, NJ, USA, 2010.

[25] C. Petterino and A. Argentino-Storino, "Clinical chemistry and haematology historical data in control Sprague-Dawley rats from pre-clinical toxicity studies," Experimental and Toxicologic Pathology, vol. 57, no. 3, pp. 213-219, 2006.

[26] T. C. Wang, Y. P. Su, T. Y. Hsu, C. C. Yang, and C. C. Lin, “28Day oral toxicity study of the aqueous extract from spider brake (Pteris multifida Poiret) in rats," Food and Chemical Toxicology, vol. 45, no. 9, pp. 1757-1763, 2007.

[27] G. D. Singh, M. Ganjoo, M. S. Youssouf et al., "Sub-acute toxicity evaluation of an aqueous extract of Labisia pumila, a Malaysian herb," Food and Chemical Toxicology, vol. 47, no. 10, pp. 2661$2665,2009$.

[28] S. T. Wolford, R. A. Schroer, P. P. Gallo et al., "Age-related changes in serum chemistry and hematology values in normal sprague-dawley rats," Toxicological Sciences, vol. 8, no. 1, pp. 8088, 1987.

[29] F. M. Poitout-Belissent and J. E. McCartney, "Interpretation of hematology data in preclinical toxicological studies," in Schalm's Veterinary Hematology, D. J. Weiss and and K. J. Wardrop, Eds., pp. 78-84, Blackwell, 2010.

[30] P. R. Sarma, "Red cell indices," in Clinical Methods: The History, Physical, and Laboratory Examinations, H. K. Walker, W. D. Hall, and J. W. Hurst, Eds., pp. 720-723, Butterworths, Boston, Mass, USA, 1990.
[31] J. D. Weiss, "Iron and copper deficiencies and disorders of iron metabolism," in Schalm's Veterinary Hematology, D. J. Weiss and K. J. Wardrop, Eds., pp. 171-176, Blackwell, 2010.

[32] A. Greinacher, B. Farner, H. Kroll, T. Kohlmann, T. E. Warkentin, and P. Eichler, "Clinical features of heparin-induced thrombocytopenia including risk factors for thrombosis A retrospective analysis of 408 patients," Thrombosis and Haemostasis, vol. 94, no. 1, pp. 132-135, 2005.

[33] J. A. Herlich, P. Taggart, J. Proctor et al., "The non-GLP toleration/dose range finding study: design and methodology used in an early toxicology screening program," Proceedings of the Western Pharmacology Society, vol. 52, pp. 94-98, 2009.

[34] A. O. Prakash, "Short term toxicity of embelin in female rats," Phytotherapy Research, vol. 8, no. 5, pp. 257-264, 1994.

[35] B. Desta, "Ethiopian traditional herbal drugs. Part I: studies on the toxicity and therapeutic activity of local taenicidal medications," Journal of Ethnopharmacology, vol. 45, no. 1, pp. 27-33, 1995.

[36] R. K. Johri, S. K. Dhar, G. S. Pahwa, S. C. Sharma, J. L. Kaul, and U. Zutshi, "Toxicity studies with potassium embelate, a new analgesic compound," Indian Journal of Experimental Biology, vol. 28, no. 3, pp. 213-217, 1990. 


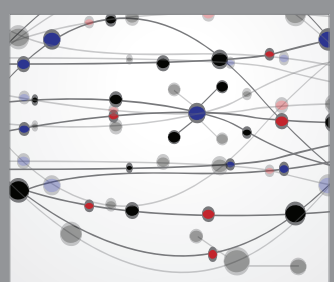

The Scientific World Journal
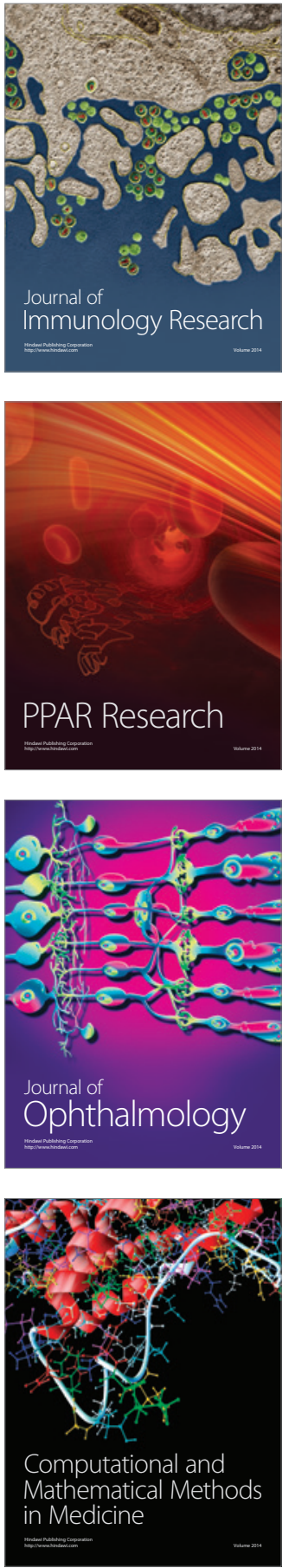

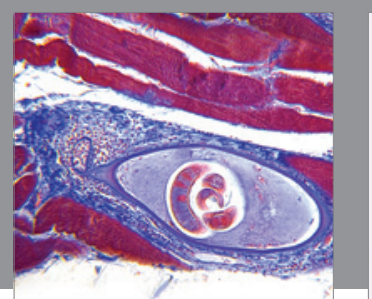

Gastroenterology Research and Practice

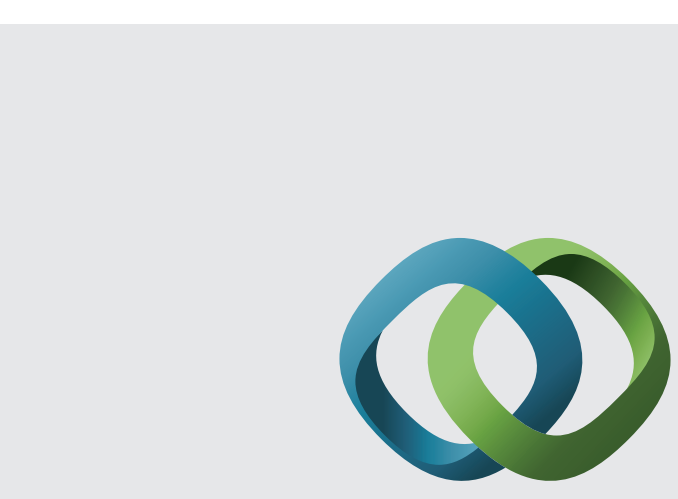

\section{Hindawi}

Submit your manuscripts at

http://www.hindawi.com
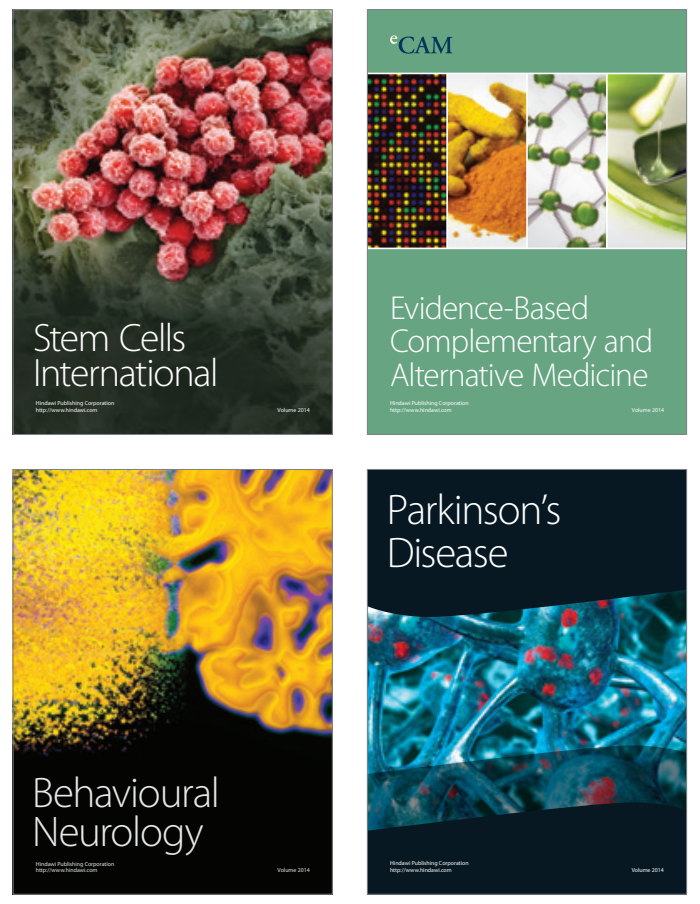
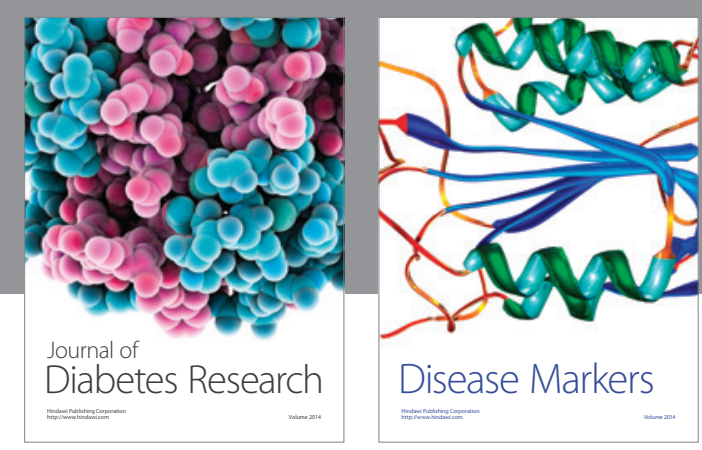

Disease Markers
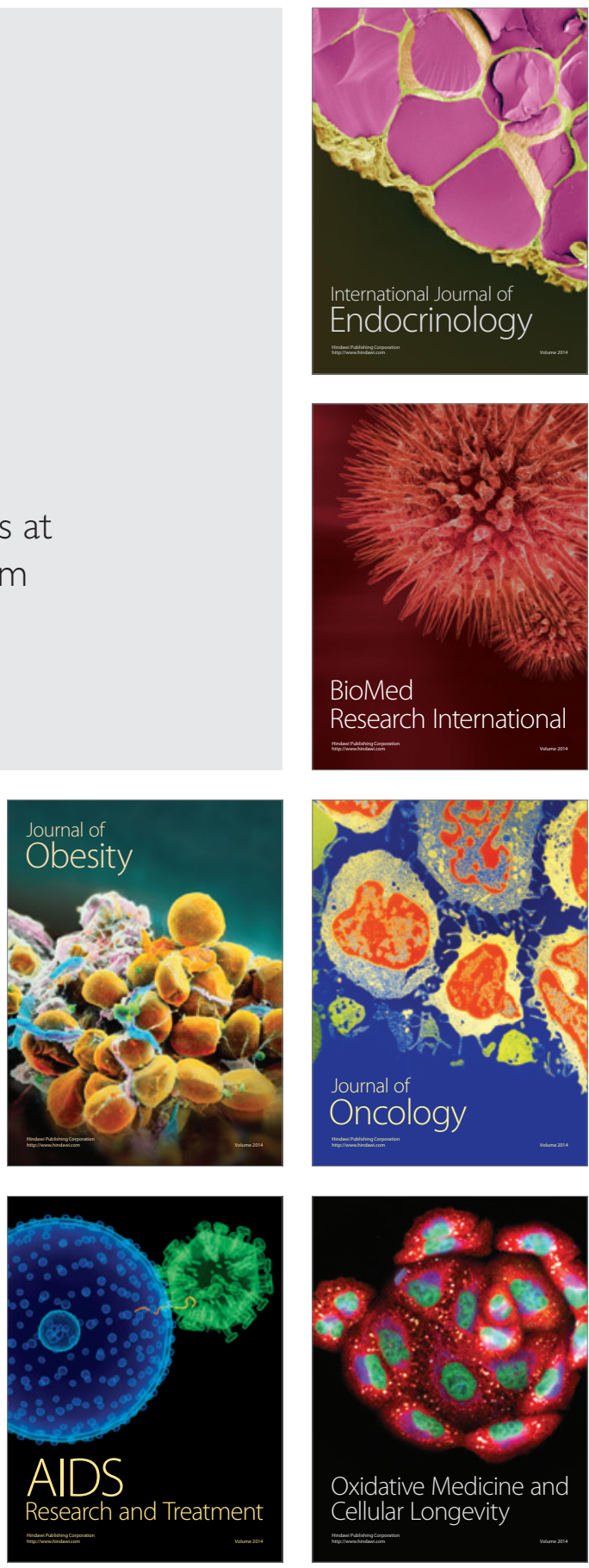